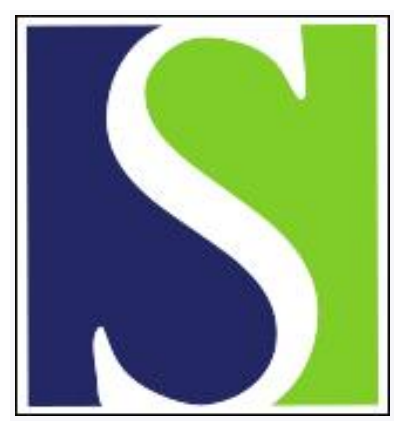

Scand J Work Environ Health 1984;10(3):189-195

https://doi.org/10.5271/sjweh.2341

Issue date: Jun 1984

Occurrence of fibrous sodium aluminumtetrafluoride particles in potrooms of the primary aluminum industry.

by Gylseth B, Bjorseth O, Dugstad O, Gjonnes J

The following article refers to this text: 1986;12(3):223

This article in PubMed: www.ncbi.nlm.nih.gov/pubmed/6548045

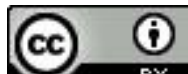




\title{
Occurrence of fibrous sodium aluminumtetrafluoride particles in potrooms of the primary aluminum industry
}

\author{
by Bjørn Gylseth, PhD, ${ }^{1}$, Olav Bjørseth, DrEng, ${ }^{2}$ Øyvind Dugstad, MSc, ${ }^{3}$ Jon Gjønnes, $\mathrm{PhD}^{3}$
}

\begin{abstract}
GYLSETH B, BJØRSETH O, DUGSTAD $\varnothing$, GJØNNES J. Occurrence of fibrous sodium aluminumtetrafluoride particles in potrooms of the primary aluminum industry. Scand $J$ Work Environ Health 10 (1984) 189-195. Inorganic fibrous particles have been found in the work environment of the primary aluminum industry. Based on scanning electron microscopic analysis, the concentrations ranged from 9 to 720 fibers/cc. The fibers were generally thinner than $0.1 \mu \mathrm{m}$ in diameter and shorter than $5 \mu \mathrm{m}$. By electron microscopy, energy dispersive $\mathrm{X}$-ray microanalysis, and selected area electron diffraction the fibers were identified as sodium aluminumtetrafluoride.
\end{abstract}

Key terms: electron microscopy, fiber concentrations, sodium aluminumtetrafluoride fibers.

As a result of research conducted by Stanton and coworkers (14) other mineral fibers than asbestos have also been focused on from an occupational health point of view. Stanton et al demonstrated that both synthetic and natural mineral fibers may possess a carcinogenic potential when implanted in the pleural cavity of animals. Though their route of administration was unphysiological and cannot be directly compared to inhalation, the results have gained great importance with respect to further research and the occupational and medical evaluation of workplaces where such fibers occur. The endemic occurrence of malignant pleural mesotheliomas in some small villages in Turkey (2), where fibrous zeolites (erionite) are found in the rocks, has given further strength to the hypothesis that other minerals than asbestos may also be carcinogenic.

The Norwegian aluminum industry has, for a long period, been the subject of great interest due to an anticipated increased risk of fluorosis due to fluoride exposure, allergic alveolitis caused probably by a mixed dust and gas exposure, and cancer due to exposure to polycyclic aromatic hydrocarbons. During a routine industrial hygiene survey in one plant, fibrous particles were observed in the airborne dust in the potrooms.

In this study we report on the identification and quantification of such inorganic fibers in the work atmosphere of the primary aluminum industry.

\footnotetext{
I Institute of Occupational Health, Oslo, Norway.

2 The Foundation of Scientific and Industrial Research at the Norwegian Institute of Technology, Trondheim, Norway.

3 Institute of Physics, University of Oslo, Oslo, Norway.
}

Reprint requests to: Dr B Gylseth, Institute of Occupational Health, POB 8149 Dep, Oslo 1, Norway.

\section{Materials and methods}

\section{Samples from the work environment}

Short-term samples from the work environment were taken by both personal and stationary sampling. For the personal samples air was filtered through Nuclepore membranes (diameter $37 \mathrm{~mm}$, pore size $0.2 \mu \mathrm{m}$ ) at a flow rate of $1.8 \mathrm{l} / \mathrm{min}$ for $1-9 \mathrm{~min}$. These specimens were used for the quantitative analysis of airborne fiber concentrations. For the stationary samples Nuclepore membranes (diameter $47 \mathrm{~mm}$, pore size $0.2 \mu \mathrm{m}$ ) were used with a flow rate of $15 \mathrm{l} / \mathrm{min}$ during sampling periods of $10-30 \mathrm{~s}$. These samples were used for the qualitative analysis.

\section{Bulk samples}

From one of the plants samples of reacted alumina and cryolite from a pot with prebaked anodes were obtained. A sample of chiolite $\left(\mathrm{Na}_{5} \mathrm{Al}_{3} \mathrm{~F}_{14}\right)$ was obtained from the Norwegian Institute of Technology.

\section{Analytical methods}

Phase contrast microscopy at $40 \times$ objective (magnification of $500 \times$ ) is recommended as the standard method for the analysis of fibers in the work environment. The fibers we were looking at were mostly far below the limit of the visibility of our phase contrast microscope (fibers $0.25 \mu \mathrm{m}$ in diameter), and therefore only electron microscopic techniques were used. Pieces of the Nuclepore membranes (air samples and filtered bulk samples) were coated with a thin film of gold or carbon to make the specimens conductive. The carbon-coated specimens were attached to 200-mesh electron microscopy grids and placed on a polyurethane sponge soaked in chloroform. After 
one night the Nuclepore membrane was dissolved, and the particles were left embedded in an electron transparent carbon film. These samples were first analyzed in a Jeol $100 \mathrm{CX}$ transmission electron microscope (TEM) fitted to a Link 860 X-ray microanalyzer [used for energy dispersive X-ray microanalysis (EDS) ] for the determination of chemical composition. Fiber dimensions were measured from micrographs taken at different magnifications. The same samples were also subject to selected area electron diffraction (SAED) analysis in a Jeol 200 CX TEM. The gold-coated samples were analyzed for fiber density in a Jeol JSM-35 scanning electron microscope (SEM) equipped with a Princeton gamma tech $1000 \mathrm{X}$-ray microanalyzer. The fibers were counted directly from the screen in the slow scanning mode at a magnification of $4,500 \times$. One hundred fibers or 100 fields, whichever was obtained first, were counted. The chemistry and morphology of the bulk samples were also analyzed by SEM.

The solubility of the fibers was investigated by the resuspension of some of the membranes in distilled water or $1 \mathrm{M}$ hydrochloric acid, respectively, and then treated for $5 \mathrm{~min}$ in an ultrasonic bath. The suspension was then refiltered on Nuclepore membranes $25 \mathrm{~mm}$ in diameter and $0.2 \mu \mathrm{m}$ in pore size and analyzed in the SEM.

\section{Results}

\section{Electron microscopy}

The fibers were found in high concentrations during the crust-breaking operation. The results are given in table 1. Figure 1 shows characteristic fibers as seen in the SEM, whereas figures 2 and 3 show the same type of fibers photographed in the TEM.

Forty-three fibers were measured from different micrographs, and the geometric mean for diameter and length was calculated. The mean diameter was 0.053 (range $0.027-0.114) \mu \mathrm{m}$ and the mean length was 0.87 (range $0.23-9.71$ ) $\mu \mathrm{m}$.

\section{Energy dispersive $X$-ray microanalysis}

General EDS revealed sodium and aluminum as the only elements present. Fluorine was probably another element present; however, it was not detected by this method.

The relation between the peak heights for sodium (Na) and aluminum (Al) will be less than the corresponding molar concentrations due to instrumental factors. Peak heights were measured from the spectra shown in figure 4 , and the data are presented in table 2. The $\mathrm{Na}: \mathrm{Al}$ peak height ratio of two fiber samples was found to be 0.20 and 0.21 , neither of which corresponds to cryolite or chiolite, with ratios of 0.80 and 0.40 , respectively. Based on the cryolite standard, every $\mathrm{Na}$ atom corresponds to a peak height of $14 \mathrm{~mm}$ and every $\mathrm{Al}$ atom to a peak height of $54 \mathrm{~mm}$, ie, $\mathrm{Na}: \mathrm{Al}=0.26$. If chiolite is used as a standard, the corresponding $\mathrm{Na}: \mathrm{Al}$ ratio is 0.24 . These results indicate that the fibers consist of equal amounts of $\mathrm{Na}$ and $\mathrm{Al}$ as in sodium aluminumtetrafluoride $\left(\mathrm{NaAlF}_{4}\right)$.

\section{Selected area electron diffraction}

Diffraction patterns from individual fibers consisted of spotty rings and arcs, as well as diffraction spots. The fibers hence are not single crystals. Dark field pictures taken with diffraction spots also indicated the fibers to be composed of many small single crystals, probably of the same type as seen in figure 3 . Most of the diffraction features are weak and difficult to measure with great accuracy. Four distinct reflections gave the $d$ values $6.24,3.70,2.87$, and $2.41 \AA$. The latter three could be attributed to several or all the possible crystal modifications cryolite, chiolite and $\mathrm{NaAlF}_{4}$. The first and strongest, at $6.24 \AA(001)$, only corresponds to $\mathrm{NaAlF}_{4}$ (15). The diffraction patterns were thus taken as a strong indication of the presence of this compound.

\section{Solubility}

Fibers without apparent signs of chemical attack were detected after $5 \mathrm{~min}$ of sonication in both distilled water and $1 \mathrm{M}$ hydrochloric acid. This finding suggests that the fibers are resistant to these liquids.

\section{Discussion}

It is evident that short thin fibers are produced during primary aluminum production. The crystals are probably produced during the recrystallization of fumes from the electrolyte. These particles will, to some extent, follow the pot gases and are collected in the dry-filtration process and thus recycled to the pots along with the reacted alumina. (Fibers were detected in the sample of reacted alumina.)

Howard (5) first demonstrated the existence of $\mathrm{NaAlF}_{4}$ in the gas phase in rapidly cooled vapors with the use of X-ray powder diffractometry. $\mathrm{He}$ claimed that the compound was unstable over $470^{\circ} \mathrm{C}$ and that the dissociation occurred according to the following equation:

$5 \mathrm{NaAlF}_{4}$ (gas phase) $=\mathrm{Na}_{5} \mathrm{Al}_{3} \mathrm{~F}_{14}$ (solid phase) + $2 \mathrm{AlF}_{3}$ (solid phase).

eq 1

Ginsberg \& Resch (4) studied rapidly cooled vapors over melted $\mathrm{NaF} / \mathrm{AlF}_{3}$ between temperatures ranging from $800-1,200^{\circ} \mathrm{C}$ by $\mathrm{X}$-ray diffractometry. They only observed diffraction lines from $\mathrm{NaAlF}_{4}$ in the $\mathrm{NaAlF}_{4}$ melt composition, while both $\mathrm{NaAlF}_{4}$ and $\mathrm{Na}_{5} \mathrm{Al}_{3} \mathrm{~F}_{14}$ were observed over melted cryolite. On the basis of this information, they assumed that the dissociation according to the aforementioned equation was not probable and suggested that it was 
$\mathrm{NaAlF}_{4}$ (gas phase) and $\mathrm{NaF}$ (gas phase) that formed chiolite during the condensation phase.

Rolin \& Houriez (9) suggested on the other hand that $\mathrm{NaAlF}_{4}$ (gas phase) dissociates according to equation 1 at temperatures below $920^{\circ} \mathrm{C}$, while the predominant reaction at temperatures above $920^{\circ} \mathrm{C}$ is:

$\mathrm{NaAlF}_{4}$ (gas phase) $=\mathrm{NaF}$ (gas phase) + $\mathrm{AlF}_{3}$ (gas phase).

Table 1. Air samples analyzed by scanning electron microscopy at a magnification of $4,500 \times$.

\begin{tabular}{lrr}
\hline Location & $\begin{array}{c}\text { Air volume } \\
\text { (I) }\end{array}$ & $\begin{array}{c}\text { Fiber concentration } \\
\text { (fibers/cc) }\end{array}$ \\
\hline Just behind the crust breaker & 1.5 & 640 \\
Two pots behind crust breaker (prebaked) & 16.2 & 190 \\
Four pots behind crust breaker (prebaked) & 14.4 & 390 \\
Filling of secondary aluminum & 8.6 & 9 \\
Two pots behind crust breaker (Søderberg) & 7.5 & 720 \\
\hline
\end{tabular}

la

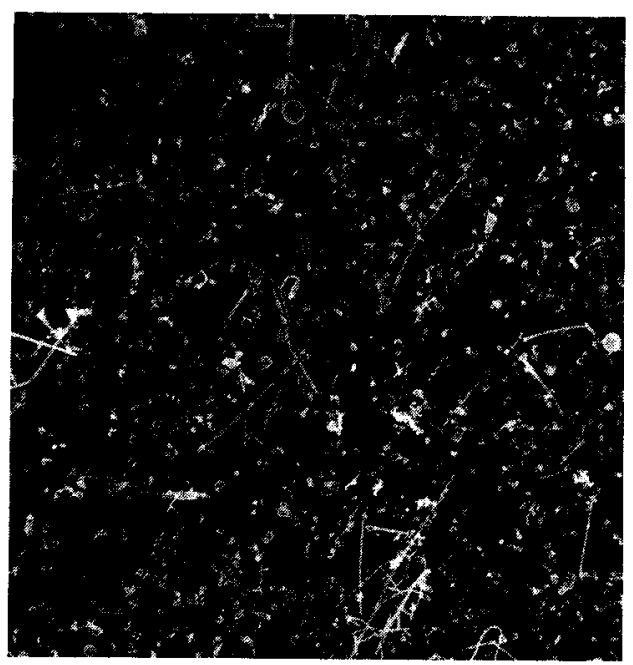

\section{$5 \mu \mathrm{m}$}

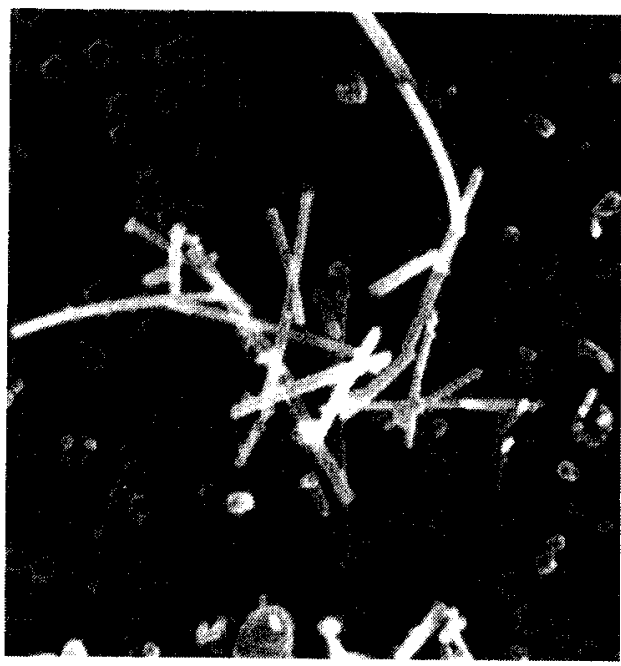

1 um

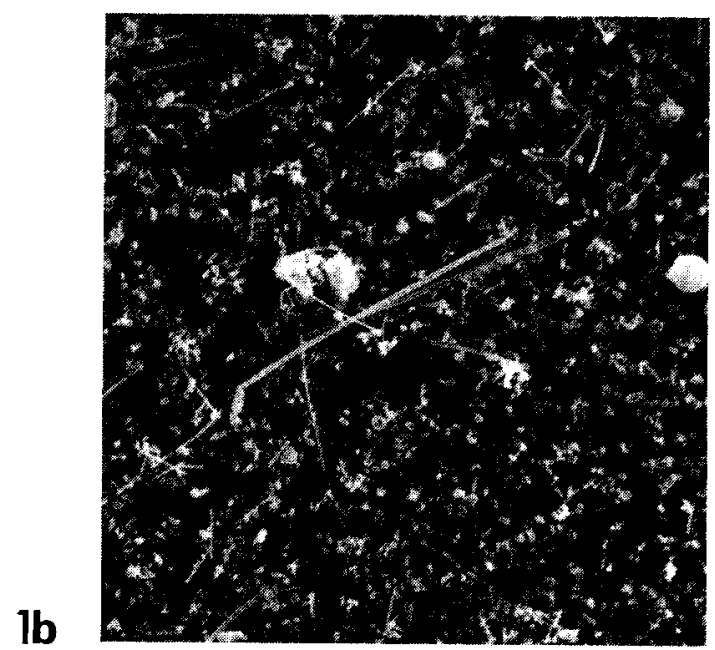

\section{$5 \mu \mathrm{m}$}

Figure 1a-c. Typical sodium aluminumtetrafluoride fibers as seen in the scanning electron microscope at different magnifications. 


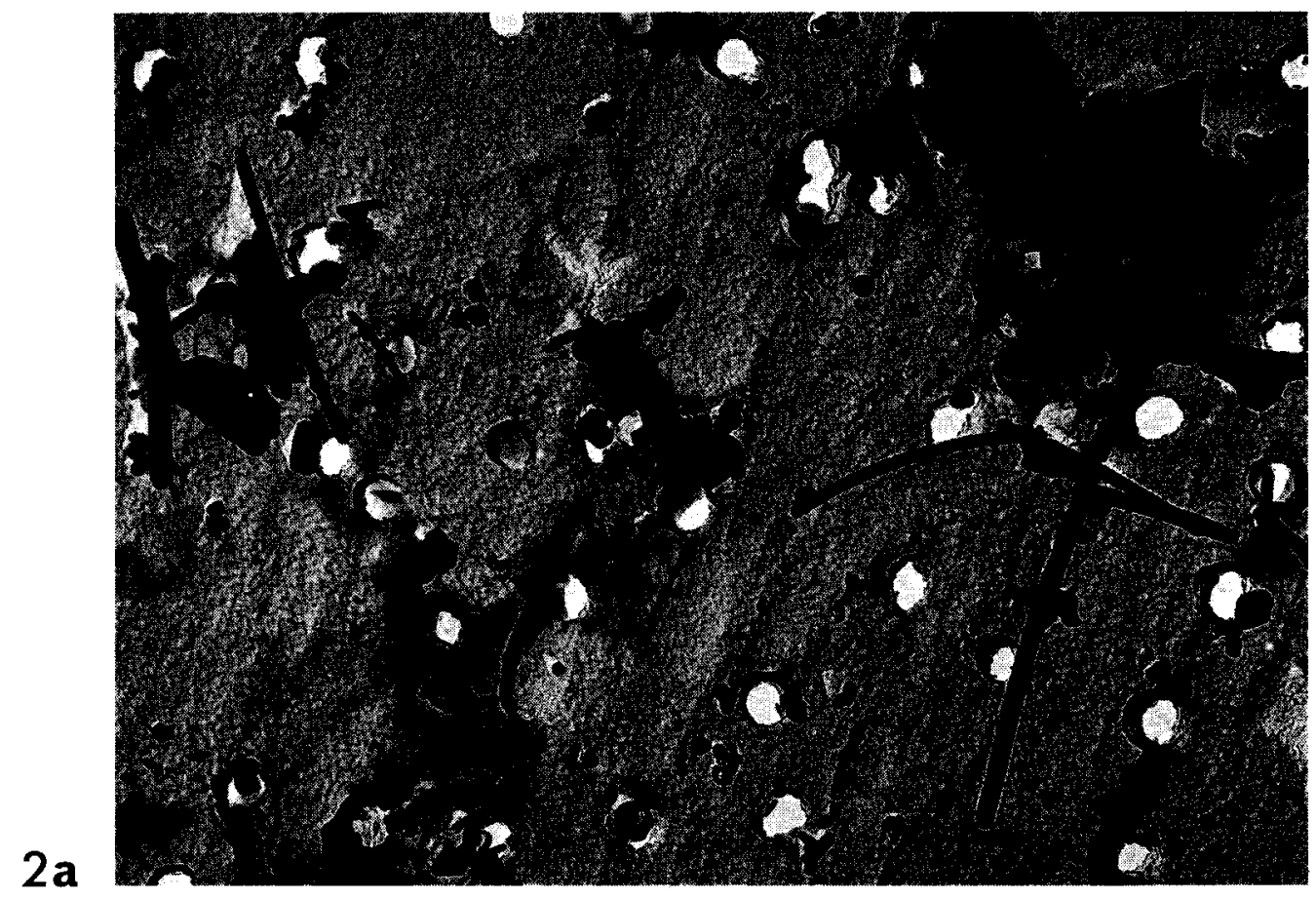

1 um

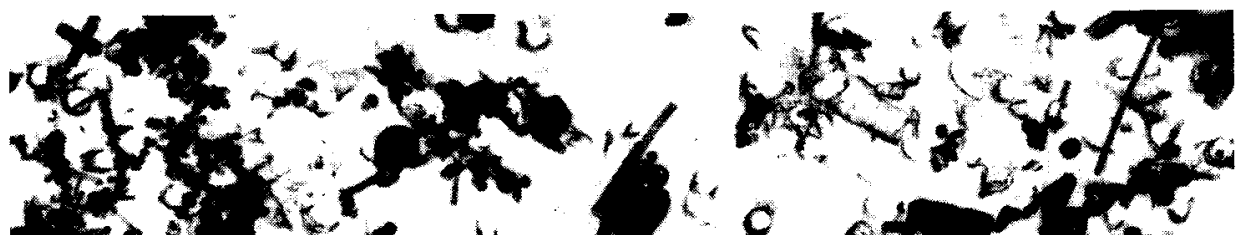

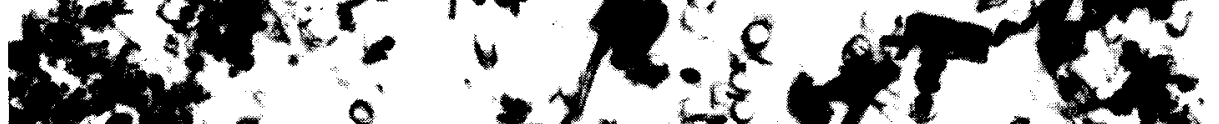

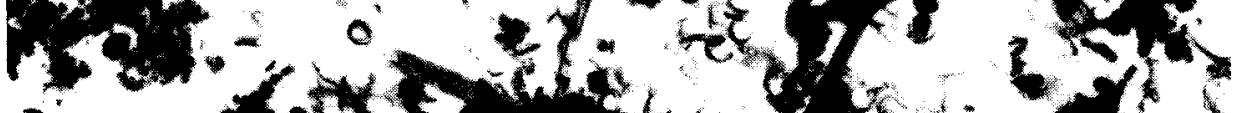

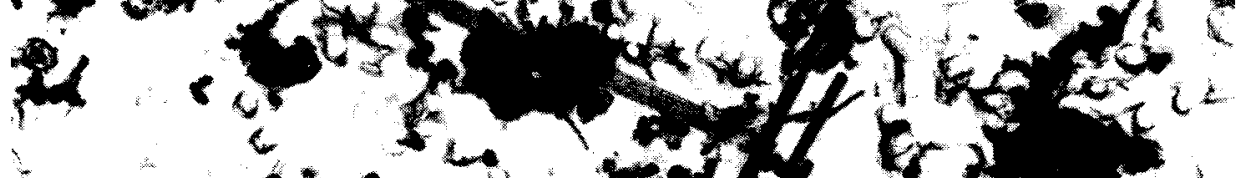

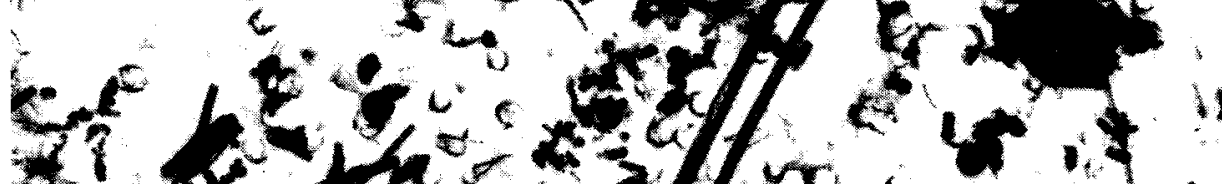

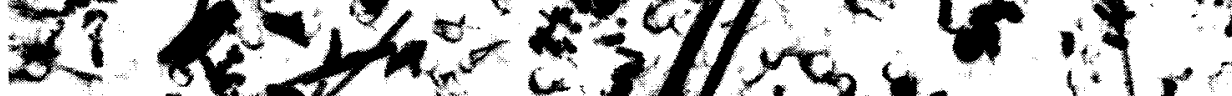

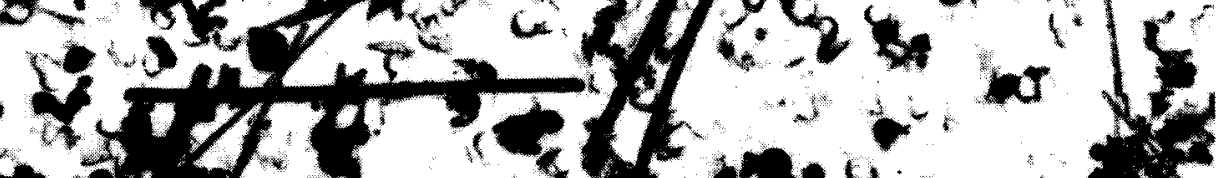

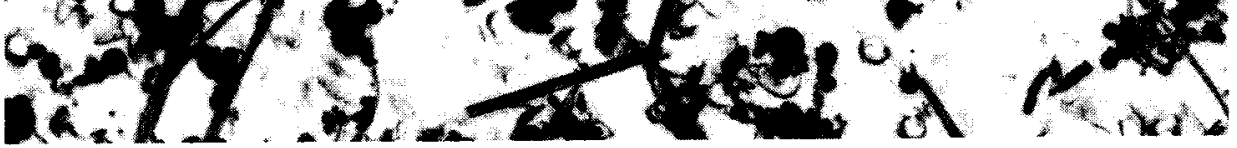

\section{$1 \mu \mathrm{m}$}

Figure 2a-b. Typical sodium aluminumtetrafluoride fibers as seen in the transmission electron microscope at different magnifications. 


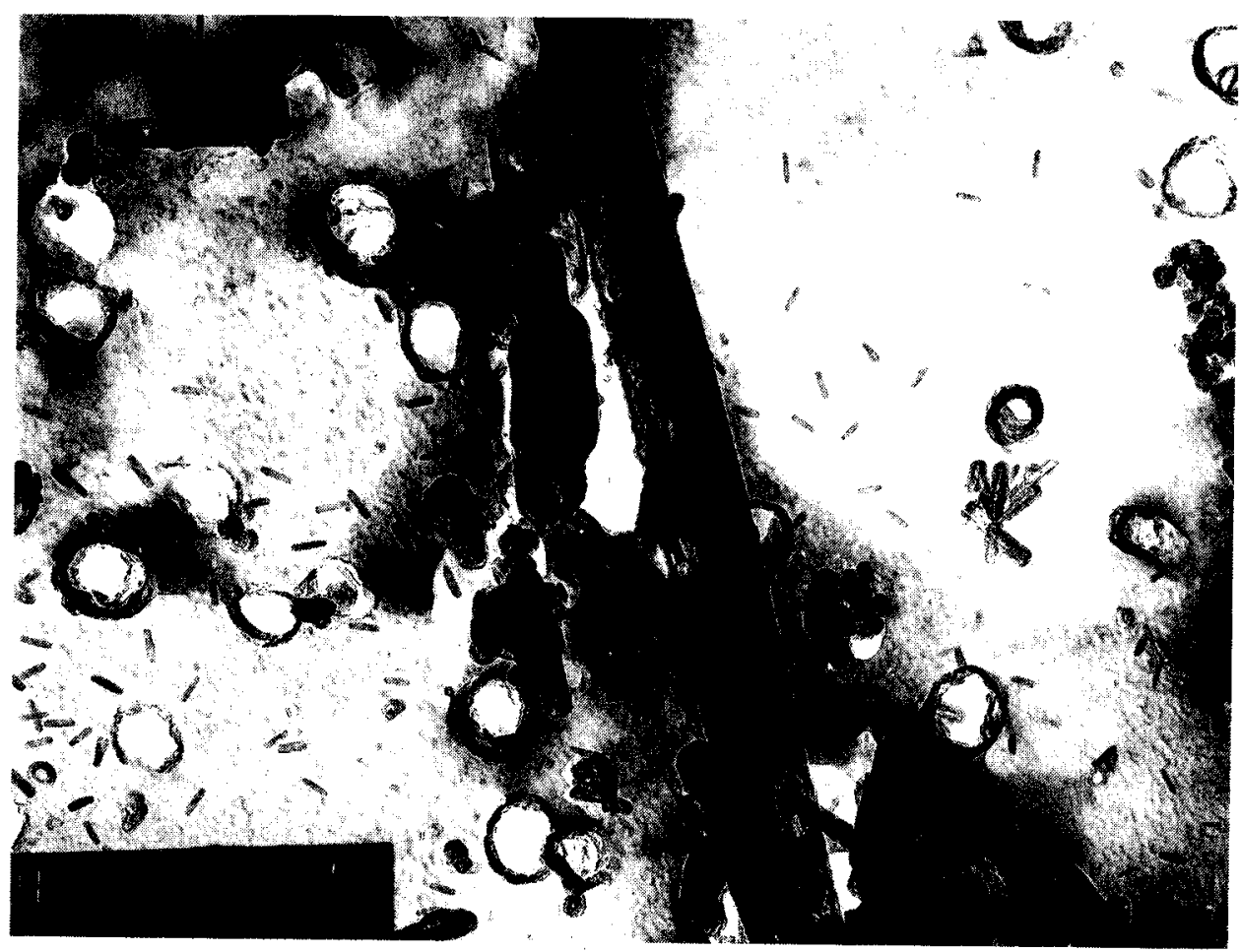

\section{$1 \mu \mathrm{m}$}

Figure 3. High magnification transmission electronmicrograph of one big fiber and several single crystal microfibers.

Table 2. Peak heights measured from energy dispersive $X$-ray spectra both from fibers and from standards of chiolite and

\begin{tabular}{llccc}
\hline Particle & Method & $\begin{array}{c}\text { Sodium } \\
(\mathrm{mm})\end{array}$ & $\begin{array}{c}\text { Aluminum } \\
\text { (mm) }\end{array}$ & $\begin{array}{c}\text { Sodium: } \\
\text { aluminum }\end{array}$ \\
\hline Cryolite $\left(\mathrm{Na}_{3} \mathrm{AlF} \mathrm{F}_{6}\right)$ & $\begin{array}{l}\text { Scanning electron microscopy - } \\
\text { energy dispersive X-ray microanalysis } \\
\text { Scanning electron microscopy - }\end{array}$ & 43 & 53 & 0.80 \\
Fiber $(?)$ & $\begin{array}{l}\text { energy dispersive X-ray microanalysis } \\
\text { Transmission electron microscopy - } \\
\text { energy dispersive X-ray microanalysis } \\
\text { Fiber }(?)\end{array}$ & 10 & 49 & 0.20 \\
Chiolite $\left(\mathrm{Na}_{5} \mathrm{Al}_{3} \mathrm{~F}_{14}\right)$ & $\begin{array}{l}\text { Scanning electron microscopy - } \\
\text { energy dispersive X-ray microanalysis }\end{array}$ & 45 & 70 & 0.21 \\
\hline
\end{tabular}

The formation and stability of $\mathrm{NaAlF}_{4}$ have been further investigated and discussed in several other reports $(3,4,6,7,10,11,12,13)$.

An increased lung cancer risk (observed: expected $=1.6$ ) has been reported in the Norwegian aluminum industry (including the plant where we measured the fibers) by Andersen et al (1). This increased cancer risk could, according to them, be attributed to several factors, among which are exposure to polycyclic aromatic hydrocarbons, a higher proportion of smokers among employees than the referents, and intercounty cancer variations in the reference population. It was emphasized that the cancer incidence of a reference population is a critical methodological problem. The observed: expected ratio of 1.6 found by Andersen et al was based on the reference incidence rates observed in the counties where the plants are located. If, however, the estimation were based on national rates, the corresponding ratio would be 1.07. More recently Rockette \& Arena (8) did not find any increased lung cancer risk in their study of aluminum reduction plant workers.

We have reported high concentrations of fibrous particles in the work environment of the primary aluminum industry; such high concentrations have previously not been described. These fibers showed re- 


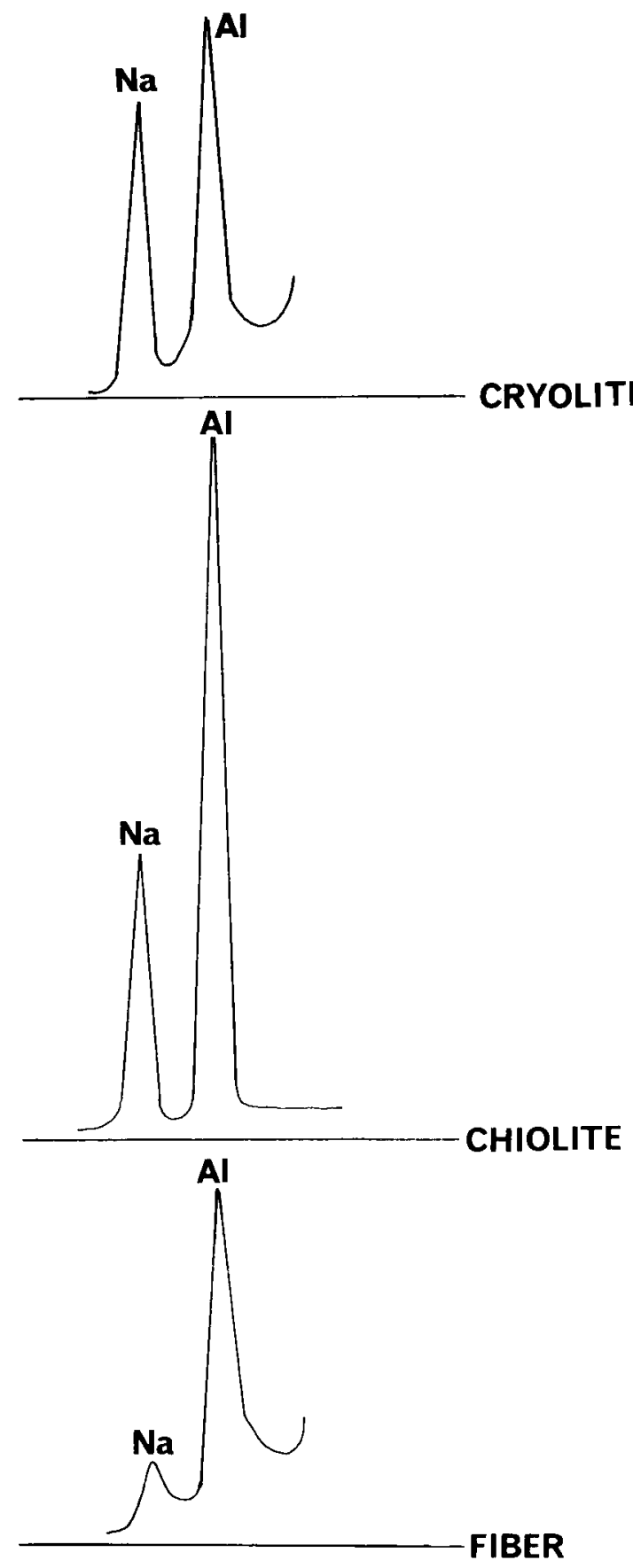

Figure 4. Energy dispersive $X$-ray spectra of standard cryolite and chiolite and one of the fibers.

sistance against dilute hydrochloric acid; however the solubility of such fibers in physiological model solutions or lung fluids has not been established. The dimensions of the fibers were rather small, and, if the dimensions are considered the most important factor from a toxicologic point of view, such fibers should not represent any carcinogenic risk. However, little is known about the health effects of short and thin durable inorganic fibers, and whether or not such fibers do represent a contribution to a health risk can so far only be a matter of speculation. In order to promote prevention, further research should be initiated, including toxicologic tests and, from an epidemiologic point of view, recordings of the concentration of these fibers at work sites in the primary aluminum industry.

\section{Acknowledgments}

The authors wish to thank Mr E Norheim, Mr J Lindstrøm, and Mr R Bjørgo for their cooperation in this study. We are grateful to Ms G Edholm and L Overaae for their technical assistance. We further acknowledge the Electron Microscopy Laboratory for Bioscience, University of Oslo, for loaning us one of the electron microscopes.

\section{References}

1. Andersen A, Dahlberg BE, Magnus $\mathrm{K}$, Wannag A. Risk of cancer in the Norwegian aluminum industry. Int J Cancer 29 (1982) 259-298.

2. Baris I, Sahin AA, Ozeani MN, Kerse I, Ozen E, Kolacan B, Altinöors M, Gøktepeli A. An outbreak of pleural mesothelioma and chronic fibrosing pleuresy in the village of Karain/Urgüp in Anatolia. Thorax 33 (1978) 181-192.

3. Büchler A, Berkowitz-Mattuck JB. In: Eyring L, ed. Adv High Temp Chem 1 (1967) 133.

4. Ginsberg H, Resch K. Beitrage zur Kenntnis des Zustandes der Salzschmelzen der Systeme NaF-AlF 3 und $\mathrm{NaF}-\mathrm{AlF}_{3}-\mathrm{Al}_{2} \mathrm{O}_{3}$. Erzmetall 13 (1960) 523-533.

5. Howard EH. Some physical and chemical properties of a new sodium aluminium fluoride. J Am Chem Soc 76 (1954) $2041-2042$.

6. Kolosov EN, Shol'ts VB, Sidorov LN. Mass spectrometric study of the thermodynamic properties of the sodium fluoride-aluminium fluoride system: III Investigation of molecular velocities with the aid of a selector: Enthalpies of dissociation of complex molecules. Russ J Phys Chem (Engl Transl) 48 (1974) 2199-2203.

7. Kvande H. Thermodynamics of the system NaF$\mathrm{AlF}_{3}$-Al studied by vapour pressure measurements. University of Trondheim, Trondheim 1979. (Doctoral dissertation)

8. Rockette HE, Arena VC. Mortality studies of aluminum reduction plant workers: Potroom and carbon department. J Occup Med 24 (1983) 549-557.

9. Rolin M, Houriez J. Etude de l'équilibre liquide vapeur de système binaire $\mathrm{NaF}-\mathrm{AlF}_{3}$. Bull Soc Chim Fr 31 (1964) 891-897.

10. Sidorov LN, Erokhin EV, Akishin PA, Kolosov EN. Investigation of the composition and vapour pressure

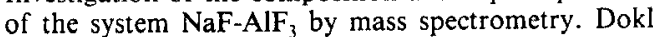
Chem 173 (1967) 265.

11. Sidorov LN, Kolosov EN. Mass spectrometric study of the thermodynamic properties of the system sodium fluoride - aluminium fluoride: I Calculation of the enthalpy and free energy of formation of sodium tetrafluoraluminate $\left(\mathrm{NaAlF}_{4}\right)$ in the gas phase. Russ $\mathrm{J}$ Phys Chem (Engl Transl) 42 (1968) 1382-1384.

12. Sidorov LN, Kolosov EN, Shol'ts VB. Mass spectrometric study of the thermodynamic properties of the system sodium fluoride - Aluminium fluoride: II Thermodynamic properties of the condensed phase in 
the system sodium fluoride - Aluminium fluoride. Russ J Phys Chem (Engl Transl) 42 (1968) 1384-1386.

13. Sidorov LN, Shol'ts VB. Mass spectrometric investigation of two-component systems of complex vapour composition by the isothermal evaporation method. Int J Mass Spectrom Ion Phys 8 (1972) 437-458.

14. Stanton MF, Layard M, Tegeris A, Miller E, May M, Morgan E, Smith A. Relation of particle dimension to carcinogenicity in amphibole asbestos and other fibrous minerals. J Natl Cancer Inst 67 (1981) 965-975.

15. Wyckoff RWG. Crystal structures. Volume 3. Interscience Publisher, New York, NY 1965.

Received for publication: 28 February 1984 